\title{
The effect of previous scar on breast reconstruction using abdominal flap: a retrospective analysis of 122 consecutive cases and a strategy to reduce complication rates
}

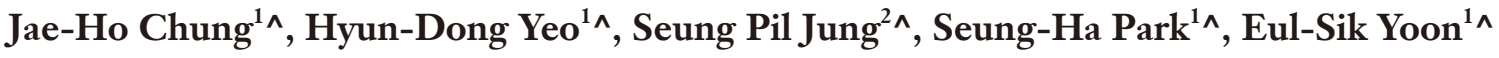 \\ ${ }^{1}$ Department of Plastic and Reconstructive Surgery, Korea University Hospital, Seoul, Republic of Korea; ${ }^{2}$ Division of Breast and Endocrine Surgery, \\ Korea University Hospital, Seoul, Korea \\ Contributions: (I) Conception and design: JH Chung, ES Yoon; (II) Administrative support: None; (III) Provision of study materials or patients: None; \\ (IV) Collection and assembly of data: JH Chung, HD Yeo; (V) Data analysis and interpretation: JH Chung; (VI) Manuscript writing: All authors; (VII) \\ Final approval of manuscript: All authors. \\ Correspondence to: Eul-Sik Yoon, MD, PhD. Department of Plastic and Reconstructive Surgery, Korea University Anam Hospital, 73, Inchon-ro, \\ Seongbuk-gu, Seoul, 02841, Korea. Email: yesanam2@korea.ac.kr.
}

\begin{abstract}
Background: Free abdominal tissue transfer is considered the gold standard for autologous breast reconstruction. However, many plastic surgeons are concerned about the theoretical risk of flap-related or donor-site complications associated with previous abdominal surgery. Also, studies have reported conflicting results in the literature due to difference in surgical strategies used in each study. This study analyzes the effect of prior incision on the complications and risk factors in our institution.

Methods: In this retrospective cohort study, we analyzed a total of 122 patients who had undergone reconstructive surgery between March 2012 and February 2019. To assess the effect of prior incision, we divided all patients into a scar group $(n=59)$ and a control group $(n=63)$. Based on our operative approach, patient demographics and postoperative complications were analyzed.

Results: No significant differences were found between patients in the scar group and the control group in flap-related $(13.3 \%$ vs. $16.4 \%, \mathrm{P}=0.62)$ and donor-site complications $(31.7 \%$ vs. $31.4 \%, \mathrm{P}=0.67)$. In binary logistic regression modeling, only diabetes mellitus was significantly related with donor-site complications $(\mathrm{P}=0.030)$.

Conclusions: This result suggested that previous abdominal scars are no longer a reluctant factor for breast reconstruction using an abdominal flap, when an appropriate flap design was used and the surgical techniques were tailored to each scar. In patients with vertical midline or subcostal scar, it requires careful preoperative planning with CT angiography and attentive follow-up are needed.
\end{abstract}

Keywords: Breast reconstruction; scar; postoperative complications; microsurgical free flap

Submitted Feb 23, 2021. Accepted for publication Mar 24, 2021.

doi: $10.21037 / g s-21-112$

View this article at: http://dx.doi.org/10.21037/gs-21-112

\footnotetext{
^ ORCID: Jae-Ho Chung, 0000-0002-8351-2444; Hyun-Dong Yeo, 0000-0002-5499-5053; Seung Pil Jung, 0000-0003-3967-2974; Seung-

Ha Park, 0000-0002-2667-2791; Eul-Sik Yoon, 0000-0001-5734-6625.
} 


\section{Introduction}

In the recent times, an increasing number of patients are undergoing autologous breast reconstruction (1). Among them, abdominal tissue transfer, such as free transverse rectus abdominis myocutaneous (TRAM) and deep inferior epigastric artery perforator (DIEP) flap have become the most commonly used reconstructive tools, based on excess abdominal tissue and ease of molding shape. However, the deleterious effects of previous abdominal scar on abdominal flap-based breast reconstruction still remain to be addressed.

Abdominal scars may affect the outcomes by disturbing perforators, altering the perfusion across the scar, weakening the abdominal fascia, and forming scar tissue that hinders flap dissection (2). In particular, vertical midline scars are often considered as a challenge to reconstructive surgeons due to the relative lack of available volume for large breast. Subcostal scar is also a concerned due to the high incidence of donor-site breakdown (3-5).

Various operative strategies to date have been suggested to improve flap survival and reduce donor-site complications in these patients. Many of them focus on the modification of flap design or minimizing dissection $(2,6)$. In case of vertical midline scar, several surgical techniques have been reported to augment contralateral side flap such as supercharging (7-9). Since, these studies employ different operative strategies each other, it is important to determine the optimal approach that improves the aesthetic outcome and reduces the postoperative complications.

The aim of this study was to find out the effects of prior abdominal surgery on the flap-related or donor-site complications, and to confirm the risk factors. We will present our experience and discuss better approaches in patients with different types of abdominal scar. We present the following article in accordance with the STROBE reporting checklist (available at http://dx.doi.org/10.21037/ gs-21-112).

\section{Methods}

\section{Patients}

This retrospective analysis was approved by the institutional review board of Korea University Anam Hospital (protocol number 2020AN0132) and performed in accordance with the principles of the Declaration of Helsinki (as revised in 2013). Individual consent for this retrospective analysis was waived. Medical records including detailed operation notes, follow-up records, and photographs were collected and analyzed. Patients who had undergone pedicled TRAM were excluded because of the small cohort size. Also, the records of patients with unclear surgical details or previous abdominal surgeries were excluded. Finally, the data of 122 patients who underwent breast reconstruction using abdominal free tissue transfer between March 2012 and February 2019 were included.

\section{Study design}

To assess the effect of previous scar on the risk of flaprelated and donor-site complications, we compared the outcomes of patients with abdominal scar ( $\mathrm{n}=59$, scar group) and the control group without any abdominal scar $(n=63)$.

\section{Flap-related complications}

Flap-related complications included total flap loss; partial flap loss, defined as tissue loss greater than $20 \%$ of the flap; and fat necrosis, defined as ischemic fat tissue characterized by subcutaneous firmness between 2 and $5 \mathrm{~cm}$ in diameter.

\section{Donor-site complications}

Donor-site complications consisted of abdominal hernia, abdominal weakness (including bulging), infection, wound dehiscence, seroma, and fat necrosis. Abdominal hernia was defined as abdominal bulge requiring operative herniorrhaphy. On the other hand, abdominal weakness included the cases of conservative treatment without any surgical procedure. Infection and wound dehiscence were defined as any abscess and wound rupture requiring operative procedures such as drainage and debridement, respectively. Seroma formation requiring additional aspirations was also included.

\section{Operative technique}

\section{Flap elevation in vertical midline scar}

In patients with vertical midline scar, we usually split the flap vertically below the infra-umbilical tissue into two hemi-flaps. In most cases, the contralateral tissues across the scar were not used as part of a flap because of unreliable perfusion. However, in 2 of 11 patients with vertical midline scar, a part of Hartrampf zone II was used to overcome the relative lack of volume (Figure 1). In these cases, the flap was observed intraoperatively during harvest, followed by assessment of perfusion to the flap across the midline scar. In no case, any tissue beyond a midline scar was included using crossover techniques such as supercharging. 

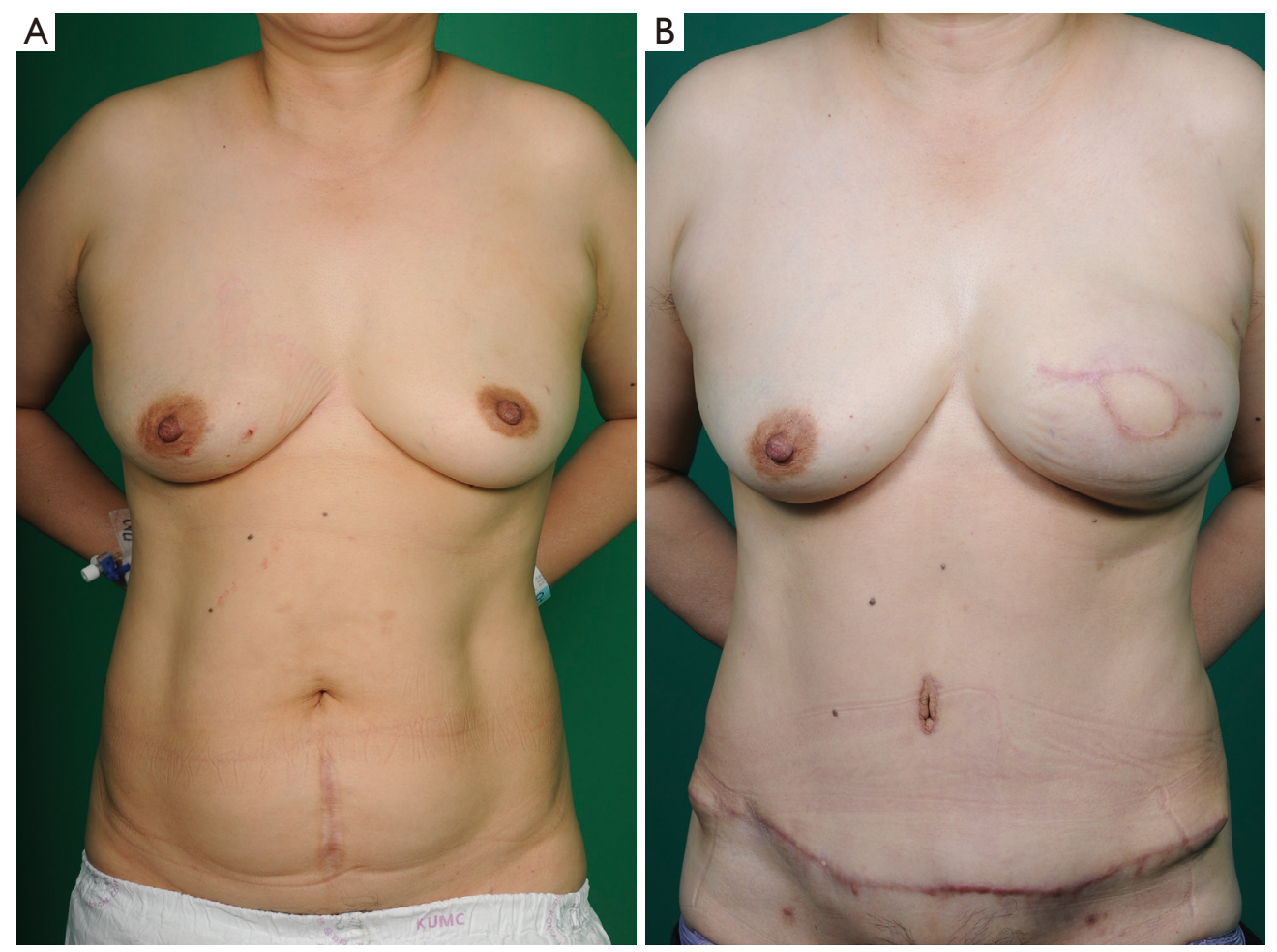

Figure 1 Representative clinical image in patient with previous vertical midline scar. A 50-year-old woman with a vertical midline scar associated with cesarean section underwent left modified radical mastectomy and immediate breast reconstruction. To overcome the relative lack of volume, the abdominal flap (MS-2 TRAM) including a part of zone II was inset. (A) Preoperative frontal view; (B) postoperative frontal view at 6 months. TRAM, transverse rectus abdominis myocutaneous.

\section{Flap elevation in other types of scar}

In most cases of Pfannenstiel scar, the abdominal flap was designed to include a low-transverse scar at the lower edge of the cutaneous island (Figure 2). However, in case of a very low transverse scar, the flap was moved upward above the scar without undermining the scar tissue. In one patient with subcostal scar, we used the contralateral side tissue, and minimized undermining over the subcostal lesion. However, in patients with scars related to appendectomy or laparoscopy, we elevated flap in a conventional manner.

\section{Donor-site closure}

Abdominal closure following flap harvest was performed under hip flexion to reduce tension. In most case, a fascial defect was small and closed primarily without tension. In case of larger fascial defect, however, a polypropylene mesh was used to provide added strength. Also, two closed suction drains were left in place to prevent seroma formation. After then, the deep fat layer was sutured with Vicryl 2-0 at 3$4 \mathrm{~cm}$ intervals. Subsequently, the dermal layer was sutured, with Vicryl 3-0 or 4-0 at 2-3 cm intervals. A subcuticular suture was performed with Monocryl 4-0 in the early period; however, from 2017, we used a barbed suture known as Stratafix 4-0 (Somerville, NJ, USA) for higher tensile strength. After wound closure, steri-strip (3M, Inc. St. Paul, $M N$, USA) and simple gauze dressing were used. Maternity belts were applied for from 4 to 6 weeks in DIEP and from 6 to 8 weeks in TRAM.

\section{Statistical analyses}

All statistical analyses were performed using SPSS version 24.0 software (IBM Corp., Redmond, WA, USA). Student's $t$-test, chi-square test and Fisher's exact test were used for statistical comparison of both groups. Also, univariate and multivariate analyses using a binary logistic regression models were performed to analyze the predictors of flaprelated or donor-site complication. In this process, we excluded the patients with subcostal $(\mathrm{n}=1)$ or laparoscopic scar $(n=2)$ because of the small numbers. For all analyses, a 

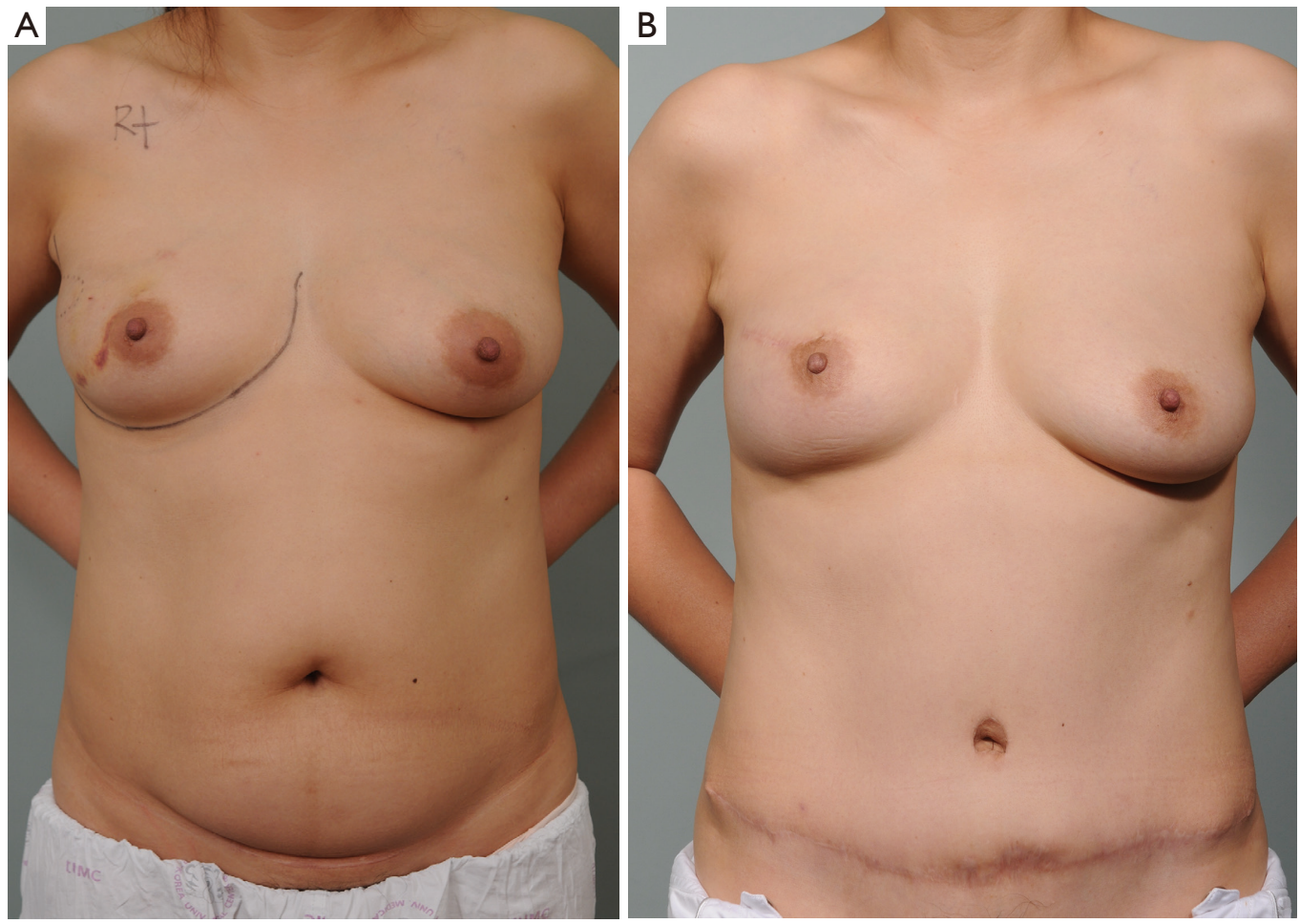

Figure 2 Representative clinical image in patient with previous Pfannenstiel scar. A 45-year-old woman with a Pfannenstiel scar underwent right nipple-sparing mastectomy and immediate breast reconstruction. The abdominal flap (MS-2 TRAM) was designed to include lowtransverse scar at the lower edge of the cutaneous island. (A) Preoperative frontal view; (B) postoperative frontal view at 1 year. TRAM, transverse rectus abdominis myocutaneous.

value of $\mathrm{P}<0.05$ was considered statistically significant.

\section{Results}

\section{Patient demographics}

We analyzed a total of 127 flaps in 122 patients including 59 patients with previous scar (60 flaps) and 63 patients without scar (67 flaps). The mean follow-up period was 18 months (range, 3-59 months). There was no significant difference between both groups regarding age, body mass index (BMI), comorbidity (hypertension and diabetes), smoking history, prior radiotherapy, chemotherapy, mastectomy weight, inset flap weight, flap type, recipient vessel, operation time and mesh use (Table 1). The most common type of scar was the low transverse (including Pfannenstiel scar, $n=42$ ), followed by vertical midline ( $\mathrm{n}=11,17.7 \%)$ and right-lower quadrant scar caused by appendectomy $(n=6,10.0 \%)$. The median time interval between pervious abdominal surgery and breast reconstruction was 12 years (range, 3 months30 years).

\section{Comparison of complication rates}

There was no significant difference between the scar group and the control group regarding flap-related complications (13.3\% vs. $16.4 \%, \mathrm{P}=0.62$, Table 2). Also, there were no significant differences in terms of partial flap loss $(5.0 \% \mathrm{vs}$. $3.0 \%, \mathrm{P}=0.66)$ and fat necrosis $(8.3 \%$ vs. $11.9 \%, \mathrm{P}=0.57)$. Only a single case of total flap loss was observed in the control group caused by Acinetobacter baumannii infection. This patient was reconstructed again with extended latissimus dorsi flap after serial surgical debridements.

No significant differences were found in the overall rate of abdominal donor-site complications of both groups (31.7\% vs. $31.4 \%, \mathrm{P}=0.67$, Table 2). Also, there were no significant differences in terms of hernia $(3.3 \%$ vs. $3.0 \%$, $\mathrm{P}=1.00)$, abdominal weakness ( $1.7 \%$ vs. $1.5 \%, \mathrm{P}=1.00)$, infection ( 0 vs. $1.5 \%, \mathrm{P}=1.00)$, wound dehiscence $(20.0 \%$ vs. $22.4 \%, \mathrm{P}=0.83)$, seroma formation $(3.0 \%$ vs. $0, \mathrm{P}=0.21)$, or fat necrosis $(6.7 \%$ vs. $3.0 \%, \mathrm{P}=0.67)$. Table 2 summarizes the rates of flap-related and donor-site complication rates in both groups. 
Table 1 Patient demographics

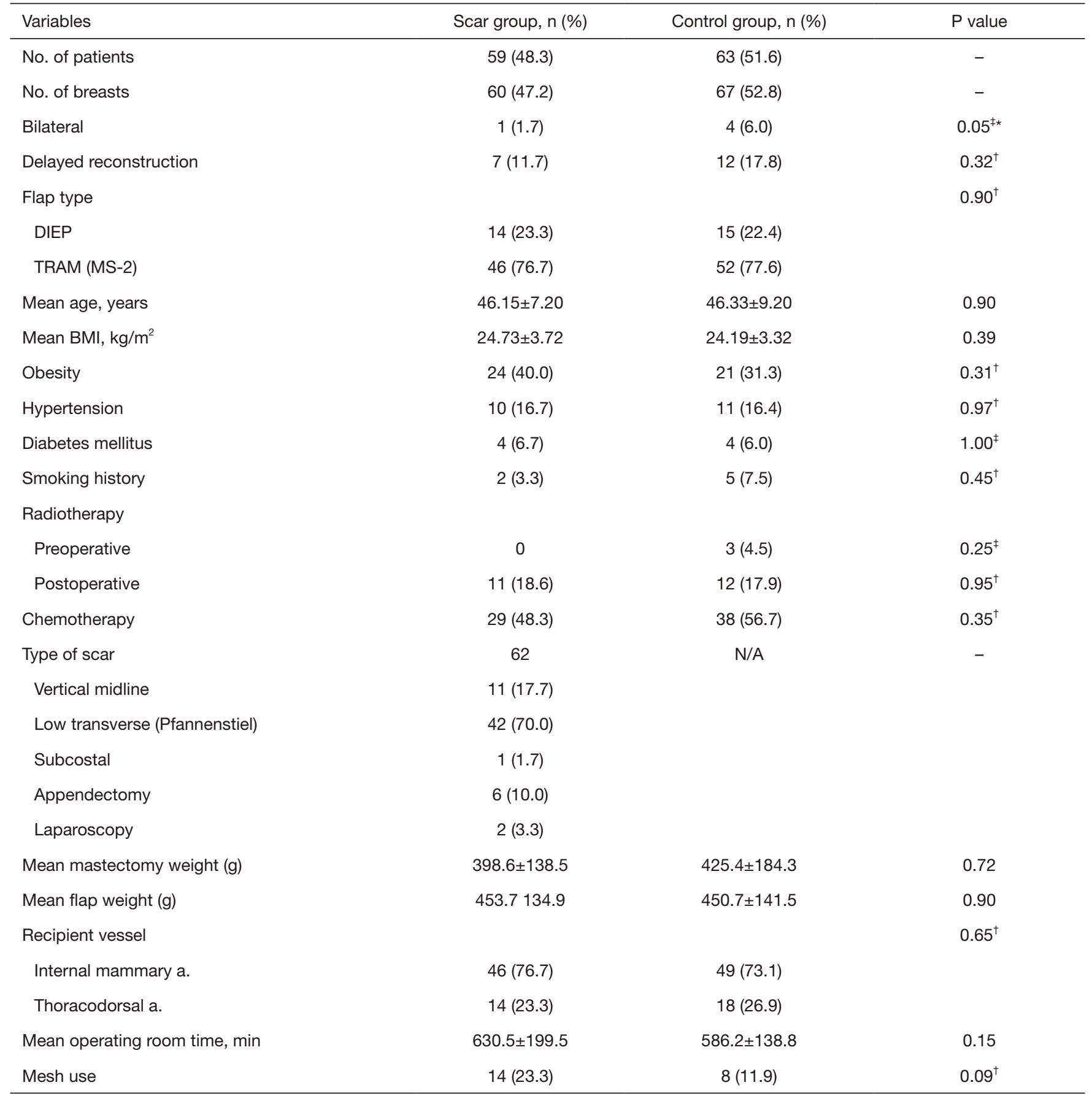

${ }^{\dagger}$, Chi-square analysis; ${ }^{\ddagger}$, Fisher's exact test; *, statistical significance. DIEP, deep inferior epigastric perforator flap; TRAM, transverse rectus abdominis myocutaneous flap; MS-2, muscle sparing type 2; BMI, body mass index.

\section{Univariate and multivariate analyses of flap-related of donor-site complications}

In binary logistic regression analysis, hypertension was related to flap-related complication with a borderline statistical significance $(\mathrm{P}=0.051$, Table 3). Multivariate regression with backward variable selection also showed a similar tendency $(\mathrm{P}=0.087)$. There was no other significant factor related to flap complications. In terms of donor-site 
Table 2 Comparison of complication rates

\begin{tabular}{lccc}
\hline Complication & Scar group, $\mathrm{n}(\%)$ & Control group, $\mathrm{n}(\%)$ & $\mathrm{P}$ value \\
\hline Flap complication & $8(13.3)$ & $11(16.4)$ & $1(1.5)$ \\
Total flap loss & 0 & $2(3.0)$ & $1.02^{\dagger}$ \\
Partial flap loss & $3(5.0)$ & $8(11.9)$ & $0.66^{\ddagger}$ \\
Fat necrosis & $5(8.3)$ & $21(31.4)$ & $0.57^{\dagger}$ \\
Donor site complication & $19(31.7)$ & $2(3.0)$ & $0.67^{\dagger}$ \\
Abdominal hernia & $2(3.3)$ & $1(1.5)$ & $1.00^{\ddagger}$ \\
Abdominal weakness & $1(1.7)$ & $1(1.5)$ & $1.00^{\ddagger}$ \\
Infection & 0 & $15(22.4)$ & $1.00^{\ddagger}$ \\
Wound dehiscence & $12(20.0)$ & 0 & $0.83^{\dagger}$ \\
Seroma & $2(3.0)$ & $2(3.0)$ & $0.21^{\ddagger}$ \\
Fat necrosis & $4(6.7)$ & $0.67^{\ddagger}$ & \\
\hline
\end{tabular}

${ }^{\dagger}$, Chi-square analysis; ${ }^{\ddagger}$, Fisher's exact test.

Table 3 Univariate and multivariate analysis: logistic regression for flap complication

\begin{tabular}{|c|c|c|c|}
\hline Independent variable & OR & $95 \% \mathrm{Cl}$ & $P$ value \\
\hline Age of $>50$ years & 0.845 & $0.346-2.065$ & 0.712 \\
\hline Obesity (BMl >25 kg/m²) & 1.148 & $0.485-2.715$ & 0.753 \\
\hline Hypertension $^{\dagger}$ & 2.834 & $0.994-8.077$ & 0.051 \\
\hline Smoking history & 1.333 & $0.245-7.264$ & 0.739 \\
\hline Previous radiotherapy & 1.661 & $0.145-19.003$ & 0.683 \\
\hline Bilateral reconstruction & 2.373 & $0.621-9.070$ & 0.206 \\
\hline Vertical midline scar & 1.103 & $0.262-4.639$ & 0.894 \\
\hline Muscle sparing & 0.652 & $0.223-1.905$ & 0.434 \\
\hline Flap weight & 1.001 & $0.998-1.004$ & 0.654 \\
\hline Operating room time & 1.001 & $0.999-1.003$ & 0.443 \\
\hline \multicolumn{4}{|l|}{ Multivariate analysis } \\
\hline Hypertension $^{\dagger}$ & 2.403 & $0.882-6.550$ & 0.087 \\
\hline
\end{tabular}

\footnotetext{
${ }^{\dagger}$, borderline statistical significance. OR, odds ratio; BMI, body mass index.
} 
Table 4 Univariate and multivariate analysis: logistic regression for donor complication

\begin{tabular}{|c|c|c|c|}
\hline Independent variable & OR & $95 \% \mathrm{Cl}$ & $P$ value \\
\hline Age of $>50$ years & 1.162 & $0.505-2.673$ & 0.724 \\
\hline Obesity $\left(\mathrm{BMI}>25 \mathrm{~kg} / \mathrm{m}^{2}\right)$ & 1.498 & $0.662-3.392$ & 0.332 \\
\hline Hypertension & 1.126 & $0.397-3.197$ & 0.824 \\
\hline Smoking history & 1.110 & $0.205-6.017$ & 0.904 \\
\hline Previous radiotherapy & 1.391 & $0.122-15.863$ & 0.791 \\
\hline Bilateral reconstruction & 8.628 & $0.429-173.7$ & 0.156 \\
\hline Vertical midline scar & 0.561 & $0.111-2.842$ & 0.485 \\
\hline Muscle sparing & 0.897 & $0.341-2.359$ & 0.826 \\
\hline Flap weight & 1.001 & $0.999-1.004$ & 0.306 \\
\hline Operating room time & 0.998 & $0.995-1.001$ & 0.123 \\
\hline \multicolumn{4}{|l|}{ Multivariate analysis } \\
\hline Diabetes mellitus* & 5.238 & $1.177-23.316$ & 0.030 \\
\hline
\end{tabular}

*, statistical significance. OR, odds ratio; BMI, body mass index.

complications, diabetes mellitus was statistically significant $(\mathrm{P}=0.030$, Table 4). Multivariate regression analysis revealed no significant factor except diabetes mellitus [odds ratio (OR) 5.238; 95\% CI, 1.177-23.316, $\mathrm{P}=0.030]$.

\section{Discussion}

Autologous breast reconstruction using abdominal flap such as the free TRAM or DIEP flap is currently considered the gold standard for plastic surgeons. However, there is still controversy regarding the effects of scarring caused by prior abdominal surgery on flap-related tor donor-site complications. Recent studies reported that the outcomes are generally not related to flap complications, but slightly higher donor-side morbidity $(2,5,10)$. Many plastic surgeons are currently focusing on minimizing these complications through an appropriate flap design and tailored operative technique.

In patients with vertical midline scar, the most obvious approach is to split the flap vertically in half. However, it could cause the relative lack of volume and interfere with reconstruction of a large breast. In addition, a review of our patients revealed that the scar group appeared to be accompanied by muscle atrophy and fatty degeneration compared to control group (Figure 3). During the early period, we used a part of zone II in two patients to overcome this shortage. However, one patient showed several donor-site complications including abdominal hernia and wound dehiscence. Subsequently, in our institution, we only used a hemi-flap and compensate for the deficiency with serial fat grafts. Similarly, Chang et al. also reported that the hemi-DIEP flap is safer method than including the tissue crossing the midline (11).

In the past decade, numerous surgical techniques, such as supercharging, have been reported to increase the volume of tissue across the midline scars (7-9). However, these techniques required more operative time and donorsite morbidity, and are not commonly used in most clinical cases. In our hospital, we used the hemi-flap with serial fat grafts rather than the above crossover techniques. If needed, double hemi flap could be used in combination. To achieve symmetry, contralateral balancing procedure including reduction mammoplasty could be also performed.

On the other side, Heller et al. reported the possibility of 

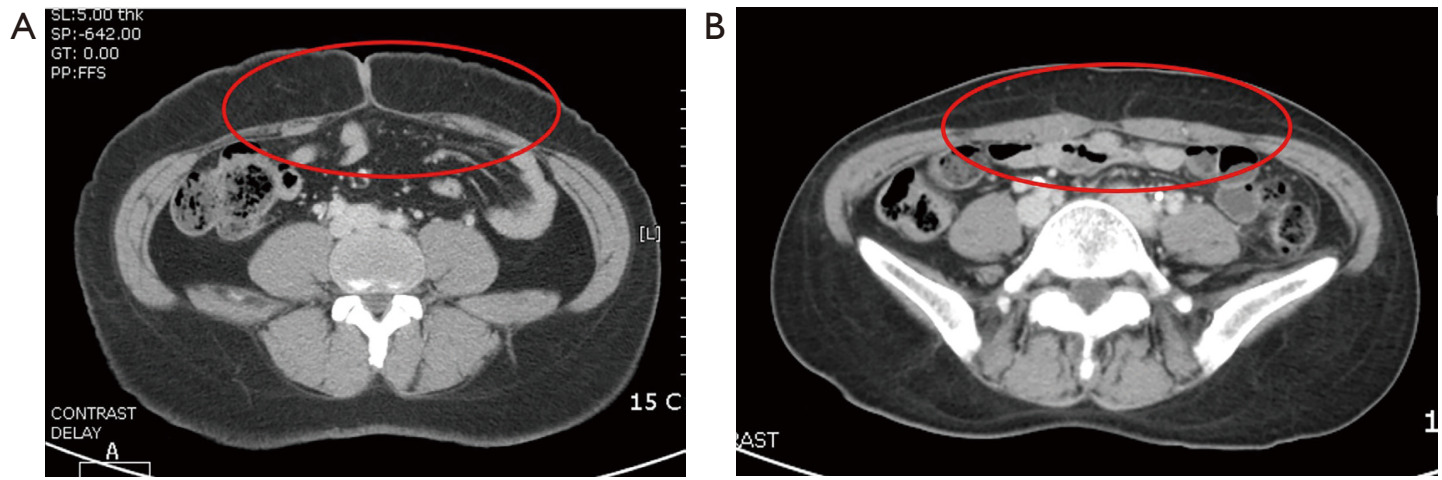

Figure 3 Comparison of axial computed tomography (CT) images between scar group and control group. The scar group (A) showed a tendency to develop higher muscle atrophy and fatty degeneration compared with the control group (B). Red circle indicates the thickness of rectus abdominis muscle in both groups.

using contralateral side without any procedure in selected cases (12). The flap was observed for 15 to 20 minutes and the perfusion was evaluated by assessing the color of skin flap and tissue bleeding. Recently, the use of indocyanine green (ICG) angiography has facilitated objective evaluation of tissue perfusion. In our institution, ICG angiography was performed routinely from 2017 to assess tissue perfusion with a near-infrared camera (Moment K; IANC\&S, Seoul, Korea).

Regarding low transverse scar, we usually designed the flap including scar at the lower edge of the cutaneous island. In univariate analysis for flap-related or donor-site complications, this type of scar showed no significant effects on complication rates $(\mathrm{P}>0.05$, Tables 3,4). Several previous studies also reported similar outcomes (13-15). Rather, Kim et al. reported that the patients with Pfannenstiel scars showed a significantly lower rate of fat necrosis compared with the control group (15). They suggested the possibility of venous preconditioning with an increase in the number of communications between superficial inferior epigastric vein (SIEV) and DIEP venae comitantes. Further, a clinical anatomic study showed that patients with Pfannenstiel scars tended to have one or more perforators and larger than $1.0 \mathrm{~mm}$ in diameter (16). In summary, breast reconstruction using TRAM or DIEP flaps could be performed safely without the risk of any complication in the patients with Pfannenstiel scar.

However, above mentioned studies are limited to the type of Pfannenstiel incision only. Pfannenstiel incisions are, of course, commonly used to access the pelvis in cesarean section operations (17). However, Pfannenstiel incision is merely one type of low transverse incisions, and does not represent other types of transverse scar. For example, Maylard incision, which is a transverse cut on the rectus abdominis muscle for gynecological surgery, is longer and higher than the Pfannenstiel incision, and it disrupts perforator vessels. Therefore, it is necessary to ascertain the perforator distribution preoperatively using a computerized tomographic angiography (CTA).

In our patient with subcostal scar, we used the contralateral free TRAM flap, and minimized undermining over subcostal lesion. However, this patient developed a wound dehiscence near a previous scar and required the secondary repair. Although we have little experience regarding subcostal scar, many studies reported that there were no significant differences in breast-related complications; however, donor-site complications were higher in the patients with subcostal scar (3-5). In particular, Losken et al. found a more than five-fold higher risk of skin necrosis on the donor-site $(26 \%$ vs. $5 \%)$ in patients with subcostal scar. To address this issue, several technical modifications were developed, such as oblique design to skew from the scar, low-rise flap design in selected patients, to leave a perforating vessel supplying the distal portion of the cranial abdominal flap below the scar were reported $(18,19)$. These approaches represent a useful option when used appropriately according to the individual characteristics of the patients.

Generally, the abdominal-wall blood supply is not altered in patients with appendectomy or laparoscopic scars $(3,6)$. In our study, among patients with appendectomy scars $(\mathrm{n}=6)$ or laparoscopic scars $(\mathrm{n}=2)$, only single patient showed a postoperative complication with a minor wound dehiscence did not require operative revision. In case of appendectomy 
scar, it was lateral to the rectus sheath, so rarely interfered with the main pedicle is rare. Also, it is usually discarded as a component of Zone IV in a patient with large abdominal pannus (4). Because these scars have little impact on flaprelated and donor-site complications, the flap can be harvested in a standard manner without concerns.

Many studies published to date have different stances each other regarding the impact of previous scar on flaprelated or donor-site complications. This appears to be due to different surgical strategies and different definitions of complications used in each study. In addition, several studies tended to have poor data reporting donor-site complications. Patients with prior abdominal scar could be poor candidates for abdominal flap than ones without scar, of course, but recent reports are in consensus that the appropriate surgical strategy suitable for each scar type could achieved an optimal outcome without disastrous complications. In our study, there were no significant differences between the scar group and the control group in regard to flap-related $(\mathrm{P}=0.62)$ and donor-site complications $(\mathrm{P}=0.67)$. The finding is consistent with recent data suggesting that previous abdominal scars are no longer a contraindication for breast reconstruction using abdominal free tissue transfer.

In logistic regression analysis, we found that only diabetes mellitus was associated with donor-site complication with a statistical significance $(\mathrm{P}=0.030)$. In terms of risk factor analysis, Doval et al. reported that smoking history and flap weight were independent risk factors for donor-site complications, especially for wound dehiscence (20). Laporta et al. also stated that smoking history and obesity (BMI $>25.1 \mathrm{~kg} / \mathrm{m}^{2}$ ) were significantly related to donor-site complications (21). In this study, there were only two smokers in the scar group, thus it seems difficult to estimate the statistical significance of the relationship between smoking and complications. However, diabetes was considered potential risk factor correlated with complications of TRAM or DIEP flaps in a previous meta-analysis (22). The aforementioned two studies did not evaluate the effect of diabetes in multivariate analysis, because it was not included as an independent risk factor.

Meanwhile, many plastic surgeons use a CTA to confirm the anatomy of perforator and to check the alteration of vasculature, especially in scarred abdomen (23-25). In our institution, we also routinely perform a CTA imaging for all patients for whom autologous breast reconstruction is planned, to preoperatively identify perforator anatomy. However, the deep inferior epigastric artery and its branches follow relatively constant anatomical course, thus a preoperative CTA isn't necessarily required (26). In review of 1,187 flaps, Daly et al. also concluded that preoperative CTA does not reduce complication rate and overall operative time (27). In our opinion, the decision whether or not to perform preoperative CTA is an option for a reconstructive surgeon. Although it is not mandatory, it could be a useful tool to help the surgeon recognize anatomical information in advance and plan operation more thoroughly.

Our study has several limitations. First, the retrospective design of this study may involve selection bias, and it did not use a perfectly matched cohort. Second, it included a relatively few patients compared with other studies, using only single-center data. In cases of patients with subcostal or laparoscopic scar, we could not include them in the logistic regression analysis because of the small numbers. Finally, it did not reflect the effect of individual wound characteristics such as the extent of wound injury or multiple scars.

\section{Conclusions}

In conclusion, when an appropriate flap design is used along with surgical techniques tailored to each scar, previous abdominal scars are no longer a reluctant factor for breast reconstruction using abdominal free tissue transfer. In patients with vertical midline and subcostal scar, it requires careful preoperative planning with CTA and attentive follow-up is needed. Diabetes mellitus increases the risk of donor-site complications, and therefore, maintenance of blood glucose level at an appropriate level is important during the perioperative period.

\section{Acknowledgments}

Funding: None.

\section{Footnote}

Reporting Checklist: The authors have completed the STROBE reporting checklist. Available at http://dx.doi. org/10.21037/gs-21-112

Data Sharing Statement: Available at http://dx.doi. org/10.21037/gs-21-112

Conflicts of Interest: All authors have completed the ICMJE uniform disclosure form (available at http://dx.doi. 
org/10.21037/gs-21-112). The authors have no conflicts of interest to declare.

Ethical Statement: The authors are accountable for all aspects of the work in ensuring that questions related to the accuracy or integrity of any part of the work are appropriately investigated and resolved. The study was conducted in accordance with the Declaration of Helsinki (as revised in 2013). The study was approved by the institutional review board of Korea University Anam Hospital (protocol number 2020AN0132). Individual consent for this retrospective analysis was waived.

Open Access Statement: This is an Open Access article distributed in accordance with the Creative Commons Attribution-NonCommercial-NoDerivs 4.0 International License (CC BY-NC-ND 4.0), which permits the noncommercial replication and distribution of the article with the strict proviso that no changes or edits are made and the original work is properly cited (including links to both the formal publication through the relevant DOI and the license). See: https://creativecommons.org/licenses/by-nc-nd/4.0/.

\section{References}

1. Matros E, Yuen JH, Bar-Meir ED, et al.

Sociodemographics, referral Patterns, and Internet Use for Decision-Making in Microsurgical Breast Reconstruction. Plast Reconstr Surg 2010;125:1087-94.

2. Parrett BM, Caterson SA, Tobias AM, et al. DIEP Flaps in Women with Abdominal Scars: Are Complication Rates Affected? Plast Reconstr Surg 2008;121:1527-31.

3. Takeishi M, Shaw WW, Ahn CY, et al. TRAM flaps in patients with abdominal scars. Plast Reconstr Surg 1997;99:713-22.

4. Hsieh F, Kumiponjera D, Malata CM. An algorithmic approach to abdominal flap breast reconstruction in patients with pre-existing scars - Results from a single surgeon's experience. J Plast Reconstr Aesthet Surg 2009;62:1650-60.

5. Losken A, Carlson GW, Jones GE, et al. Importance of right subcostal incisions in patients undergoing TRAM flap breast reconstruction. Ann Plast Surg 2002;49:115-9.

6. Nykiel M, Hunter C, Lee GK. Algorithmic approach to the design and harvest of abdominal flaps for microvascular breast reconstruction in patients with abdominal scars. Ann Plast Surg 2015;74 Suppl 1:S33-40.

7. Pennington DG, Nettle WJ, Lam P. Microvascular augmentation of the blood supply of the contralateral side of the free transverse rectus abdominis musculocutaneous flap. Ann Plast Surg 1993;31:123-6.

8. Berrino P, Casabona F, Adami M, et al. The "parasite" TRAM flap for autologous tissue breast reconstruction in patients with vertical midabdominal scars. Ann Plast Surg 1999;43:119-26.

9. Hsieh F, Somia N, Lam TC. A new approach to preexisting vertical midline abdominal scars with crossover DIEP flap breast reconstruction. Microsurgery 2010;30:151-5.

10. Roostaeian J, Yoon AP, Sanchez IS, et al. The effect of prior abdominal surgery on abdominally based free flaps in breast reconstruction. Plast Reconstr Surg 2014;133:247e-255e.

11. Chang CC, Huang JJ, Wu CW, et al. A Strategic approach for DIEP flap breast reconstruction patients with a vertical midline abdominal scar. Ann Plast Surg 2014;73 Suppl 1:S6-11.

12. Heller L, Feledy JA, Chang DW. Strategies and options for free TRAM flap breast reconstruction in patients with midline abdominal scars. Plast Reconstr Surg 2005;116:753-9.

13. Dayhim F, Wilkins EG. The impact of Pfannenstiel scars on TRAM flap complications. Ann Plast Surg 2004;53:432-5.

14. Mahajan AL, Zeltzer A, Clase KE, et al. Are Pfannenstiel scars a boon or a curse for DIEP flap breast reconstructions? Plast Reconstr Surg 2012;129:797-805.

15. Kim SY, Lee KT, Mun GH. The Influence of a Pfannenstiel Scar on Venous Anatomy of the Lower Abdominal Wall and Implications for Deep Inferior Epigastric Artery Perforator Flap Breast Reconstruction. Plast Reconstr Surg 2017;139:540-8.

16. Niumsawatt V, Chow KL, Shen XY, et al. The Pfannenstiel scar and its implications in DIEP flap harvest: a clinical anatomic study. Eur J Plast Surg 2016;39:41-8.

17. Ayers JW, Morley GW. Surgical incision for cesarean section. Obstet Gynecol 1987;70:706-8.

18. Hamdi M, Larsen M, Craggs B, et al. Harvesting free abdominal perforator flaps in the presence of previous upper abdominal scars. J Plast Reconstr Aesthet Surg 2014;67:219-25.

19. Schoeller T, Huemer GM, Kolehmainen M, et al. Management of subcostal scars during DIEP-flap raising. Br J Plast Surg 2004;57:511-4.

20. Doval AF, Lamelas AM, Daly LT, et al. Deep Inferior Epigastric Artery Perforator Flap Breast Reconstruction in Women with Previous Abdominal Incisions: A Comparison 
of Complication Rates. Ann Plast Surg 2018;81:560-4.

21. Laporta R, Longo B, Sorotos M., et al. Tips and tricks for DIEP flap breast reconstruction in patients with previous abdominal scar. Microsurgery 2017;37:282-92.

22. Wang XL, Liu LB, Song FM, et al. Meta-analysis of the safety and factors contributing to complications of MSTRAM, DIEP, and SIEA flaps for breast reconstruction. Aesthetic Plast Surg 2014;38:681-91.

23. Ngaage LM, Hamed R, Oni G, et al. The Role of CT Angiography in Assessing Deep Inferior Epigastric Peforator Flap Patency in Patients with Pre-existing Abdominal Scars. J Surg Res 2019;235:58-65.

24. Rozen WM, Garcia-Tutor E, Alonso-Burgos A, et al. The effect of anterior abdominal wall scars on the vascular anatomy of the abdominal wall: A cadaveric and clinical

Cite this article as: Chung JH, Yeo HD, Jung SP, Park SH, Yoon ES. The effect of previous scar on breast reconstruction using abdominal flap: a retrospective analysis of 122 consecutive cases and a strategy to reduce complication rates. Gland Surg 2021;10(5):1598-1608. doi: 10.21037/gs-21-112 study with clinical implications. Clin Anat 2009;22:815-22.

25. Teunis T, Heerma van Voss MR, Kon M, et al. CTangiography prior to DIEP flap breast reconstruction: a systematic review and meta-analysis. Microsurgery 2013;33:496-502.

26. Heo C, Yoo J, Minn K, et al. Circummuscular variant of the deep inferior epigastric perforator in breast reconstruction: importance of preoperative multidetector computed tomographic angiography. Aesthetic Plast Surg 2008;32:817-9.

27. Daly LT, Doval AF, Lin SJ, et al. Role of CTA in Women with Abdominal Scars Undergoing DIEP Breast Reconstruction: Review of 1,187 Flaps. J Reconstr Microsurg 2020;36:294-300. 